\title{
RUANG KERJA INKLUSIF BAGI TENAGA KERJA DENGAN DISABILITAS FISIK
}

\author{
Monica Kristiani Widhawati, Meilanny Budiarti Santoso, \\ dan Nurliana Cipta Apsari \\ Universitas Padjadjaran Jatinangor Sumedang Jawa Barat \\ Email: monicakrstn@gmail.com
}

\begin{abstract}
To achieve a better condition in living, everyone has the rights to equal opportunity, one of which through providing rights to employment at formal work sector either government owened or private owned companies for people with physical disabilities. However, to fulfill the rights required long adaptation process, and involving various connecting factors on the process of social acceptance of the workforce with physical disabilities on the formal work sector. Using literature study, this article is describing the factors influencing the acceptance of the workforce with physical disabilities as well as the opportunities to gain employment at formal sector occupation. The study found that Indonesian government have attempt to fulfill the rights of people with physical disability through the issuance of several regulations ensuring the population of people with physical disabilities in equal opportunity to employment as well as protecting them from discrimination in the formal employment surrounding. In the process, there are various factors influencing the acceptance of workforce with physical disabilities which are internal and external factors. There is an acceptance quota of people with physical disabilities to be accepted that is serves as supporting factors, meanwhile, there is also preventing factors influencing the optimalization of workforce with physical disabilities in their workplace. This writing recommends the people with physical disabilities being facilitated in enhancing their skills and knowledge in order to be qualified with the requirements of the workplace.
\end{abstract}

Keywords: physical disabilities; workforce; equal work opportunity; work opportunity

Abstrak. Dalam pencapaian kehidupan yang lebih baik setiap orang berhak akan kesempatan yang sama, salah satunya melalui pemberian hak untuk mendapatkan kesempatan kerja yang sama pada sektor kerja formal milik pemerintah maupun perusahaan swasta termasuk bagi orang dengan disabilitas fisik. Namun, ternyata untuk dapat mewujudkan hal tersebut harus melalui proses adaptasi yang cukup panjang, serta melibatkan berbagai faktor yang berkaitan pada penerimaan sosial tenaga kerja dengan disabilitas fisik pada sektor kerja formal. Menggunakan metode kajian pustaka, tulisan ini berusaha menggambarkan situasi penyebab dan peluang orang dengan disabilitas fisik dalam mendapatkan pekerjaan di sektor formal. Hasil penelitian menemukan bahwa pemerintah Indonesia telah berupaya untuk dapat memenuhi hak orang dengan disabilitas fisik dengan menerbitkan beberapa peraturan yang dapat menjamin populasi orang dengan disabilitas fisik dalam mendapatkan kesempatan kerja dan melindungi mereka dari diskriminasi di dunia kerja formal. Pada prosesnya terdapat beberapa faktor yang mempengaruhi penerimaan tenaga kerja dengan disabilitas fisik yaitu terdiri dari faktor internal dan faktor eksternal. Terdapat aturan kuota penerimaan orang dengan disabilitas fisik untuk bekerja yang menjadi faktor pendukung diterimanya orang dengan disabilitas fisik di tempat kerja formal, akan tetapi ada pula faktor penghambat orang dengan disabilitas fisik bekerja secara optimal di tempat kerja nya. Tulisan ini menyarankan agar orang dengan disabilitas fisik difasilitasi untuk meningkatkan keterampilan dan pengetahuan agar mereka dapat memenuhi persyaratan untuk penerimaan lowongan pekerjaan.

Kata kunci: disabilitas fisik; tenaga kerja; keseteraan kerja; kesempatan kerja. 


\section{Pendahuluan}

Undang-undang nomor 13 tahun 2003 tentang ketenagakerjaan pasal 1, mengemukakan bahwa "tenaga kerja adalah setiap orang yang mampu melakukan pekerjaan guna menghasilkan barang dan/atau jasa baik untuk memenuhi kebutuhan sendiri maupun untuk masyarakat". Dengan ketentuan tambahan, penduduk yang termasuk tenaga kerja menurut Badan Pusat Statistik adalah penduduk usia kerja, berkisar usia 15-64 tahun atau termasuk dalam usia produktif. Namun, di Indonesia, lapangan pekerjaan yang ada belum bisa menampung semua jumlah tenaga kerja yang tersedia, sehingga menimbulkan persaingan dalam mendapatkan pekerjaan, tidak terkecuali pada orang dengan disabilitas.

Tabel 1.

Distribusi Penyandang Disabilitas di Indonesia

\begin{tabular}{|c|l|c|}
\hline No. & \multicolumn{1}{|c|}{ Jenis Disabilitas } & Persentase \\
\hline 1 & Fisik & $10,3 \%$ \\
\hline 2 & Visual & $7,9 \%$ \\
\hline 3 & Pendengaran & $2,7 \%$ \\
\hline 4 & Bicara & $6,7 \%$ \\
\hline 5 & Mengingat/Konsentrasi & $29,6 \%$ \\
\hline 6 & Tidak bisa mengurus diri & $2,8 \%$ \\
\hline 7 & Ganda & $40 \%$ \\
\hline
\end{tabular}

Sumber: Economic and Social Commision for Asia and The Pacific (ESCAP)

United Nations (2016)

Keberadaan orang dengan disabilitas fisik di Indonesia tidak dapat dihindarkan. Tahun 2016, jumlahnya menyumbang persentase yang cukup banyak, namun tidak secara otomatis membuat aksesibilitas mereka mendapatkan pekerjaan pada dunia kerja formal menjadi lebih mudah. Mayoritas orang dengan disabilitas fisik, bahkan tidak mendapatkan kesempatan untuk memperoleh pekerjaan karena berbagai macam hambatan.

Dalam menanggapi masalah tersebut terdapat upaya yang berusaha dilakukan oleh pemerintah, berupa pembuatan beberapa undang-undang yang memberikan perlindungan kepada tenaga kerja dengan disabilitas. Melalui Kementerian Tenaga Kerja yang bekerjasama dengan berbagai pihak, pemerintah berupaya mewujudkan langkah konkret memberikan kesempatan kerja yang sama kepada setiap lapisan masyarakat, khususnya pada masyarakat 


\section{Ruang Kerja Inklusif Bagi Tenaga Kerja dengan Disabilitas Fisik}

- Monica Kristiani Widhawati, Meilanny Budiarti Santoso, dan Nurliana Cipta Apsari

yang mempunyai keterbatasan secara fisik atau disabilitas fisik berupa pelaksanaan program-program yang mendukung peningkatan kualitas tenaga kerja agar dapat memenuhi kriteria di tempat kerja formal.

Program-program tersebut dilaksanakan dalam bentuk pelatihan untuk memperdalam kemampuan yang sudah dimiliki, seperti kemampuan penggunaan jaringan berbasis komputer dan kegiatan magang yang pada awal bulan April 2018 lalu diresmikan dengan tujuan menyiapkan tenaga kerja yang berkompeten untuk memenuhi kebutuhan industri. Pemerintah juga menyediakan program pelatihan bagi tenaga kerja orang dengan disabilitas untuk memperbesar kesempatan mereka mendapatkan pekerjaan. Mereka mendapatkan perhatian khusus dari pemerintah dalam menjalankan kemajuan pembangunan negara Indonesia. Dirjen Pembinaan Penempatan Tenaga Kerja (Binapenta) pada tahun 2014 menyebutkan bahwa terdapat 1,5 juta penganguran yang merupakan orang dengan disabilitas. Sedangkan Pusat Data dan Informasi (Pusdatin) Departemen Sosial RI pada tahun 2008 mencatat sebesar $74,4 \%$ orang dengan disabilitas adalah pengangguran/tidak bekerja, dan sebesar $25,6 \%$ orang dengan disabilitas memiliki pekerjaan. Jenis pekerjaan orang dengan disabilitas berdasarkan besaran persentase adalah sebagai petani $(39,9 \%)$, buruh $(32,1 \%)$ dan jasa $(15,1 \%)$. Data tersebut menunjukkan bahwa masih sangat jarang orang dengan disabilitas bekerja pada sektor formal.

Keadaan persaingan dunia kerja formal yang mengharuskan seseorang memiliki pengalaman dan sertifikat pendidikan yang layak menjadi salah satu penghambat besar dalam penyerapan tenaga kerja dengan disabilitas. Hasil survey Arbeiter Samariter Bund (2014) dalam Margaretha (tanpa tahun) menyebutkan bahwa 70,1\% orang dengan disabilitas tidak memiliki pekerjaan (hanya diam di rumah saja) dan 43,7 \% dari orang dengan disabilitas yang bekerja menjalankan pekerjaan sebagai buruh harian atau serabutan.

Menurut ILO (2013) sebagian besar dunia kerja yang menerima tenaga kerja dengan orang dengan disabilitas adalah dunia kerja non formal yang membutuhkan keahlian rendah dengan pembayaran upah kerja yang rendah pula. Situasi ini menyebabkan upaya pemutusan rantai kemiskinan di lingkungan orang dengan disabilitas semakin berat. International Labour Organization (konvensi PBB mengenai hak-hak disabilitas) atau disingkat dengan UNCRPD, sebuah organisasi internasional yang berperan aktif dalam memperjuangkan hak-hak disabilitas, menyebutkan: (1) sekitar 15 persen dari jumlah penduduk 
di dunia sebanyak lebih dari satu miliar orang adalah orang dengan disabilitas, mereka terbilang kelompok minoritas terbesar di dunia; (2) lebih dari 80\% orang dengan disabilitas hidup dan tinggal di negara-negara berkembang. Mereka sering menghadapi keterbatasan akses terhadap kesehatan, pendidikan, pelatihan dan pekerjaan yang layak, sehingga memaksa mereka untuk hidup di bawah garis kemiskinan; (3) orang dengan disabilitas tergolong lebih rentan terhadap kemiskinan di setiap negara, baik diukur dengan indikator ekonomi tradisional seperti PDB atau secara lebih luas dalam aspek keuangan nonmoneter seperti standar hidup, misalnya pendidikan, kesehatan dan kondisi kehidupan; (4) perempuan dengan disabilitas berpotensi memiliki risiko lebih besar dibandingkan dengan laki-laki disabilitas. Kemiskinan mereka terkait dengan sangat terbatasnya peluang mereka atas pendidikan dan pengembangan keterampilan;

(5) hampir sebanyak 785 juta perempuan dan laki-laki dengan disabilitas berada pada usia kerja, namun mayoritas dari mereka tidak bekerja. Mereka yang bekerja umumnya memiliki pendapatan yang lebih kecil dibandingkan dengan para pekerja yang non-disabilitas di perekonomian informal dengan perlindungan sosial yang minim atau tidak sama sekali; (6) para orang dengan disabilitas kerap kali terkucilkan dari pendidikan, pelatihan kejuruan dan peluang kerja; dan (7) lebih dari 90 persen anak-anak dengan disabilitas di negara-negara berkembang tidak bersekolah (UNESCO) sementara hanya $1 \%$ perempuan dengan disabilitas bisa membaca (UNDP).

Fakta yang diungkapkan oleh UNCRPD (2011) menunjukkan banyaknya permasalahan dan hambatan yang dihadapi oleh orang dengan disabilitas untuk dapat bertahan hidup, terlebih untuk dapat memanfaatkan peluang dan kesempatan untuk dapat bekerja.

\section{Metode}

Artikel ini disusun dengan menggunakan metode studi literatur dan dokumen, yaitu literatur berupa buku-buku, artikel jurnal, ataupun berbagai jenis tulisan lainnya dan berbagai hasil kajian serta dokumen yang terkait dengan topik ruang kerja inklusif bagi tenaga kerja dengan disabilitas fisik.

\section{Hasil dan Diskusi}

\section{Acceptance in the Workplace for Person with Physical Disability}




\section{Ruang Kerja Inklusif Bagi Tenaga Kerja dengan Disabilitas Fisik}

- Monica Kristiani Widhawati, Meilanny Budiarti Santoso, dan Nurliana Cipta Apsari

\section{Pengertian Disabilitas Menurut WHO}

Istilah disabilitas telah mengalami banyak perubahan sepanjang sejarahnya sesuai dengan perkembangan pemahaman manusia mengenai istilah disabilitas itu sendiri. World Health Organization (WHO) dalam Santoso \& Apsari (2017) mengemukakan beberapa unsur dalam dari disabilitas yang masuk ke dalam klasifikasi ICIDH (International Classification of Impairments, Disabilitas and Handicap). Unsur-unsur tersebut adalah impairment, disability, dan handicap (Santoso \& Apsari, 2017). Impairement adalah berkaitan dengan dimensi fisik tubuh manusia yang terganggu, tidak normal atau bahkan hilang fungsinya. Sedangkan disability mengacu pada adanya gangguan pada aktifitas sebagai akibat dari adanya impairment yang telah dijelaskan sebelumnya. Sementara itu, handicap merupakan unsur dimensi lingkungan sosial dan fisik yang melingkupi orang dengan adanya impairment, disability, yang mencegahnya dari pemenuhan peranan yang normal (dalam konteks usia, jenis kelamin, serta faktor budaya) bagi orang yang bersangkutan (Pertiwi, 2011).

\section{Undang-Undang Perlindungan Disabilitas}

Undang-undang Nomor 4, 1997 tentang Penyandang Cacat pasal 1 menyebutkan bahwa orang dengan disabilitas adalah setiap orang yang mempunyai kelainan fisik dan/atau mental, yang dapat mengganggu atau merupakan rintangan dan hambatan baginya untuk melakukan secara selayaknya yang terdiri dari: orang dengan disabilitas fisik, orang dengan disabilitas mental, orang dengan disabilitas fisik dan mental. Undang-undang Nomor 19 tahun 2011 tentang Pengesahan Convention on the Right of Person with Disabilities (Konvensi Mengenai Hak-hak Orang dengan disabilitas) pasal 1 juga menyebutkan bahwa orang dengan disabilitas termasuk mereka yang memiliki keterbatasan fisik, mental, intelektual, atau sensorik dalam jangka waktu lama di mana ketika berhadapan dengan berbagai hambatan, hal ini dapat menghalangi partisipasi penuh dan efektif orang dengan disabilitas dalam masyarakat berdasarkan kesetaraan dengan yang lain.

Undang-Undang Nomor 8 tahun 2016 tentang Penyandang Disabilitas pasal 11 yang berisi jaminan dalam memperoleh pekerjaan yang diselenggarakan oleh Pemerintah, Pemerintah Daerah, atau swasta tanpa diskriminasi, serta memperoleh upah yang sama dengan tenaga kerja yang bukan Orang dengan disabilitas dalam jenis pekerjaan dan tanggung jawab yang sama. Jaminan 
berupa Undang-Undang Ketenagakerjaan yang diresmikan oleh pemerintah ditujukan agar setiap lapisan masyarakat dapat memiliki kehidupan yang layak melalui kesempatan kerja yang sama.

Semenjak dikeluarkannya perlindungan hak orang dengan disabilitas melalui Undang-Undang No. 8 tahun 2016 belum ada kemajuan yang signifikan mengenai akses terhadap pilihan pekerjaan bagi orang dengan disabilitas. Pemerintah atau pun instansi terkait juga belum mengeluarkan sansksi bagi perusahaan yang tidak memperkenankan orang dengan disabilitas untuk bekerja.

\section{Program Penerimaan Tenaga Kerja Disabilitas Fisik}

Penerimaan orang dengan disabilitas fisik di tempat kerja membutuhkan konsistensi dan dukungan dari kepemimpinan, serta kesediaan dan kesepakatan setiap anggota perusahaan untuk mengubah budaya kerja agar lebih ramah terhadap perbedaan dalam keragaman yang ada di tempat kerja. Robbin dan Judge (2014) menyatakan bahwa organisasi menggunakan berbagai upaya untuk memanfaatkan keragaman, termasuk perekrutan dan pemilihan kebijakan. Praktik pelatihan dan pengembangan tenaga kerja yang efektif dan program yang komprehensif untuk mendorong keragaman yang memiliki tiga komponen yang berbeda.

Pertama, mengajarkan manajer mengenai kerangka hukum tentang peluang kerja yang setara dan mendorong perlakuan yang adil bagi semua terlepas dari karakteristik demografis. Kedua, mengajarkan manajer tentang keragaman tenaga kerja akan lebih mampu melayani pasar yang beragam dari pelanggan dan klien. Ketiga, mendorong praktik pengembangan pribadi yang meningkatkan keterampilan dan kemampuan untuk semua pekerja, mengakui perbedaan dalam perspektif positif sehingga dapat menjadi cara yang berharga untuk meningkatkan kinerja semua karyawan.

\section{Hambatan Penerimaan Orang dengan Disabilitas Fisik di Tempat Kerja}

Dalam upaya penerimaan yang dilakukan oleh tempat kerja sektor formal terhadap tenaga kerja dengan disabilitas fisik, terdapat pula hambatan, yaitu adanya faktor internal dan faktor eksternal yang menjadi masalah dalam penerimaan orang dengan disabilitas di tempat kerja. Faktor internal pada orang dengan disabilitas yang sering ditemui adalah masalah psikologis, 


\section{Ruang Kerja Inklusif Bagi Tenaga Kerja dengan Disabilitas Fisik}

- Monica Kristiani Widhawati, Meilanny Budiarti Santoso, dan Nurliana Cipta Apsari

seperti rendah diri. Greenspan dalam Kauffman dan Hallahan (2006:11) mengemukakan bahwa orang dengan disabilitas sangat peduli pada body image, penerimaan dari teman-teman, kebebasan, penerimaan diri sendiri, dan pencapaian prestasi. Akibatnya, mereka sensitif atau sangat mudah marah pada orang lain bahkan kepada dirinya sendiri. Dengan keadaan faktor internal tersebut, orang-orang di sekitar orang dengan disabilitas harus mempunyai kesiapan untuk lebih peka, bukan menyingkirkan dan mendiskriminasi. Sejalan dengan hasil penelitian Machdan dan Hartini (2012) yang menemukan bahwa terdapat korelasi negatif dan signifikan antara penerimaan diri dan kecemasan. Artinya, semakin tinggi penerimaan diri terhadap keadaan mereka dengan keterbatasannya maka semakin rendah kecemasan yang akan mereka alami dan begitu juga sebaliknya.

Kemudian faktor eksternal yang menjadi pertimbangan perusahaan untuk mempekerjakan orang dengan disabilitas adalah stigma negatif yang berkembang di masyarakat. Macy (1996) mengemukakan hal tersebut terjadi karena masyarakat cenderung memunculkan stereotip bahwa keterbatasan fisik orang dengan disabilitas berbanding lurus dengan tingkat intelektualitas yang dimiliki. Mereka masih dianggap kurang berpendidikan dan tidak memiliki keterampilan kerja karena keterbatasannya. Arief Burhan Effendi (2017) telah melakukan penelitian mengenai 'Implementasi Diversity Program bagi Tenaga Kerja Penyandang Disabilitas pada PT. Wangta Agung Kota Surabaya' dan menunjukkan hasil bahwa perusahaan tersebut telah memberikan kesempatan kerja bagi penyandang disabilitas untuk dapat menjadi bagian tenaga kerja pada sektor produksi, tetapi belum disertai dengan pengawasan, fasilitas khusus, program pelatihan khusus, perlindungan keselamatan khusus bagi tenaga kerja dengan disabilitas untuk membuat meraka tetap dapat bekerja dengan nyaman. Pada dua penelitian yang telah dijelaskan di atas, bahwa faktor pembangun penerimaan internal dan eksternal bagi disabilitas merupakan hal yang penting.

\section{Kesetaraan Kesempatan Kerja}

Pemberian hak untuk mendapatkan kesempatan kerja yang sama kepada orang dengan disabilitas diatur melalui UU nomor 8 tahun 2016 tentang Penyandang Disabilitas dan UU nomor 4 tahun 1997. Pasal 1 ayat 3 UU nomor 4 tahun 1997 mengatur kesamaan kesempatan bagi orang dengan disabilitas yaitu keadaan yang memberikan peluang kepada orang dengan disabilitas 
untuk mendapatkan kesempatan yang sama dalam segala aspek kehidupan dan penghidupan. Kesamaan kesempatan yang dijelaskan dalam UU tersebut meliputi kesamaan kesempatan untuk mendapatkan pendidikan pada semua jalur, jenis, dan jenjang sesuai dengan jenis dan derajat disabilitasnya. Begitupun dalam mendapatkan pekerjaan, orang dengan disabilitas pun mempunyai kesamaan kesempatan untuk mendapatkan pekerjaan.

Pasal 45 dalam UU No 8 tahun 2016 menyebutkan bahwa "Pemerintah dan Pemerintah Daerah wajib menjamin proses rekrutmen, penerimaan, pelatihan kerja, penempatan kerja, keberlanjutan kerja dan pengembangan karier yang adil dan tanpa diskriminasi kepada orang dengan disabilitas". Masih dalam UU tersebut, disebutkan dalam pasal 47 bahwa pemberi kerja dalam proses rekrutmen tenaga kerja orang dengan disabilitas dapat: 1) melakukan ujian penempatan untuk mengetahui minat, bakat, dan kemampuan; 2) menyediakan asistensi dalam proses pengisian formulir aplikasi dan proses lainnya yang diperlukan; 3) menyediakan alat dan bentuk tes yang sesuai dengan kondisi disabilitas; 4) memberikan keleluasaan dalam waktu pengerjaan tes sesuai dengan kondisi orang dengan disabilitas.

Kesetaraan kesempatan untuk mendapatkan pekerjaan bagi orang dengan disabilitas dipertegas dalam pasal 14 UU nomor 4 tahun 1997, yaitu bahwa perusahaan dan swasta dituntut memberikan kesempatan dan perlakuan yang sama kepada orang dengan disabilitas dengan mempekerjakan orang dengan disabilitas di perusahaannya dengan jenis dan derajat disabilitas, pendidikan, dan kemampuannya yang jumlahnya disesuaikan dengan jumlah karyawan dan kualifikasi perusahaan. Pasal 53 UU nomor 8 tahun 2016 yang berbunyi: 1) Pemerintah, Pemerintah Daerah, Badan Usaha Milik Negara, dan Badan Usaha Milik Daerah wajib mempekerjakan paling sedikit 2\% (dua persen) orang dengan disabilitas dari jumlah pegawai atau pekerja; 2) perusahaan swasta wajib mempekerjakan paling sedikit 1\% (satu persen) orang dengan disabilitas dari jumlah pegawai atau pekerja.

Hal ini merupakan upaya pemerintah untuk memberikan kepastian mengenai besaran kesempatan peluang dan kesempatan yang tersedia bagi para orang dengan disabilitas untuk dapat bekerja pada sektor pemerintahan ataupun pada perusahaan swasta. Pasal 5 (UU nomor 13 tahun 2003) mengatur mengenai kesamaan kesempatan, yaitu bahwa setiap kerja mempunyai hak dan kesempatan yang sama untuk memperoleh pekerjaan dan penghidupan 


\section{Ruang Kerja Inklusif Bagi Tenaga Kerja dengan Disabilitas Fisik}

- Monica Kristiani Widhawati, Meilanny Budiarti Santoso, dan Nurliana Cipta Apsari

yang layak tanpa membedakan jenis kelamin, suku, ras, agama, dan aliran politik sesuai dengan minat dan kemampuan tenaga kerja yang bersangkutan, termasuk perlakuan yang sama terhadap para orang dengan disabilitas.

Mengenai kesempatan kerja dijelaskan dalam Peraturan Pemerintah Republik Indonesia nomor 33 tahun 2013 tentang Perluasan Kesempatan Kerja PP itu menyebutkan bahwa yang dimaksud dengan kesempatan kerja adalah lowongan pekerjaan yang diisi oleh pencari kerja dan pekerja yang sudah ada. Kesempatan kerja ditunjukkan dengan jumlah orang yang bekerja pada suatu saat (Haryani, 2002). Kesempatan kerja bagi orang dengan disabilitas ditunjukkan dengan seberapa banyak lowongan pekerjaan yang diisi oleh orang dengan disabilitas serta seberapa banyak yang masih tersedia untuk orang dengan disabilitas yang belum bekerja. Dalam memanfaatkan peluang dan kesempatan ruang kerja yang tersedia bagi orang dengan disabilitas dan dalam memenuhi kuota kesempatan kerja yang tersedia, terdapat beberapa faktor pendukung dan penghambat bagi orang dengan disabilitas untuk dapat melakukannya. (Feminasary, 2017):

Faktor pendukung meliputi: 1) adanya aturan yang jelas yang tercantum dalam UU nomor 8 tahun 2016 tentang Orang dengan disabilitas; 2) adanya kesempatan atau lowongan kerja bagi orang dengan disabilitas; 3) adanya kecocokan atau minat bagi orang dengan disabilitas dengan pekerjaan yang ditawarkan; dan 4) adanya kompetensi, kualitas dan kemampuan yang dimiliki oleh orang dengan disabilitas. Sedangkan faktor penghambat meliputi: 1) tempat kerja yang tidak sesuai dengan orang dengan disabilitas; 2) orang dengan disabilitas tidak memiliki minat dan bakat; 3) SDM perusahaan belum memiliki konsep yang khusus dalam merekrut dan berkomunikasi dengan orang dengan disabilitas; 4) adanya kriteria minimal usia dan minimal pendidikan dalam proses rekrutment oleh perusahaan; dan 5) pihak perusahaan terkadang tidak mencantumkan di dalam pengumuman lowongan kerja mereka bahwa lowongan kerja tersebut juga dibuka bagi orang dengan disabilitas walaupun sebenarnya mereka membuka lowongan kerja juga bagi orang dengan disabilitas.

Faktanya, orang dengan disabilitas sering kesulitan mengakses pendidikan, pelatihan kejuruan dan peluang kerja. Padahal, orang dengan disabilitas yang memiliki pendidikan dan keterampilan baik itu umum maupun khusus berkesempatan lebih besar untuk mendapatkan pekerjaan dan pendapatan yang lebih baik. Pendidikan dan keterampilan baik umum ataupun khusus juga 
akan mempengaruhi cara pandang orang dengan disabilitas terhadap dirinya sendiri. Orang dengan disabilitas yang memiliki pendidikan dan keterampilan akan menilai bahwa dirinya lebih mampu untuk bekerja, sehingga harapannya untuk mendapatkan pekerjaan akan lebih tinggi. Hal ini sejalan dengan yang diungkapkan oleh Faturochman (2012), bahwa semakin tinggi pendidikan dan semakin banyak pengalaman seseorang akan semakin tinggi pula harapan yang dimilikinya.

Orang dengan disabilitas yang mengikuti pendidikan formal serta mengikuti kegiatan keterampilan yang dapat menunjangnya dalam dunia kerja seharusnya tidak mengalami penolakan dalam mendapatkan pekerjaan hanya karena alasan disabilitas dan diharapkan juga mendapatkan kesempatan dari masyarakat. Pada kenyataannya, masyarakat sering kali mendiskriminasikan orang dengan disabilitas, walaupun mereka memiliki keterampilan untuk bekerja (Fatmawati, 2015).

Faktor lain yang dapat mendukung adanya penerimaan orang dengan disabilitas fisik di termpat kerja adalah pembangunan lingkungan kerja yang lebih kohesif, kolaboratif, dan kreatif, serta upaya dalam mempunyai kesamaan paham mengenai penerimaan inklusi dalam dunia kerja. Inklusi dapat diartikan sebagai sebuah pendekatan untuk membangun dan mengembangkan lingkungan yang semakin terbuka, mengajak masuk dan mengikutsertakan semua orang dengan berbagai perbedaan latar belakang, karakteristik, kemampuan, status, kondisi, etnik, budaya dan lainnya dengan meniadakan hambatan. Terbuka dalam konsep lingkungan inklusi juga mempunyai arti semua orang yang tinggal, berada dan beraktivitas dalam lingkungan keluarga, sekolah ataupun masyarakat merasa aman dan nyaman mendapatkan hak dan melaksanakan kewajibannya.

Miller dan Katz (2002) menyebut inclusion adalah rasa memiliki, merasa dihormati, dihargai untuk setiap keunikan yang dimiliki seseorang, merasa mendapat dukungan dan komitmen dari orang lain/lingkungan sehingga seseorang dapat memaksimalkan kapasitasnya. Inklusi melibatkan setiap individu dalam organisasi dan menempatnya sebagai misi organisasi. Pemahaman terhadap pengertian inklusif pada tahap awal penerimaan tenaga kerja difabel pada lingkungan kerja sangat penting, karena akan mempermudah pengubahan konsep atau cara pandang terhadap tenaga kerja difabel, serta tanpa disadari dapat juga mengubah suasana tempat dengan motivasi, kinerja, 


\section{Ruang Kerja Inklusif Bagi Tenaga Kerja dengan Disabilitas Fisik}

- Monica Kristiani Widhawati, Meilanny Budiarti Santoso, dan Nurliana Cipta Apsari

dan semangat yang baru dengan adanya keterbukaan.

Selanjutnya dalam mencapai inklusi menurut Lembaga Administrasi Negara RI (2011) perlu didukung oleh budaya kerja yang dilandasi oleh beberapa hal. Pertama, melalui internalisasi nilai-nilai seluruh karyawan sehingga menjadi gigih, sungguh-sungguh dan memiliki komitmen yang tinggi yang mendorong pelalaksanaan sistem kerja yang inklusif. Nilai menurut Kreitner dan Kinicki (2011) dapat dibedakan menjadi dua tipe, yaitu nilai-nilai yang disertakan atau disebutkan secara eksplisit (espoused values) dan nilainilai yang dilaksanakan (enacted values). Kedua, simbol/atribut yang dipakai juga secara psikologis dapat meningkatkan kepercayaan baik di kalangan elemen perusahaan maupun pelanggan, misalnya pakaian kerja atau aksesoris lain yang memberi kesan inklusif. Ketiga, sikap dan perilaku ini mencangkup pemahaman dan penghargaan terhadap diversity.

ILO (2011) dalam laporannya menggambarkan bahwa beberapa perusahaan di Indonesia sudah mulai mempekerjakan orang dengan disabilitas dan menyadari bahwa orang dengan disabilitas pun adalah orang-orang yang produktif, dapat diandalkan dan menguntungkan bagi perusahaan. Oleh karena itu beberapa perusahaan di Indonesia mulai mempekerjakan orang dengan disabilitas tersebut sebagai pegawai honorer, seperti: 1) P.T. Indosiar Visual Mandiri; 2) Indonesia Prosperity Trade Union Confederation (KSBSI); 3) National Vocational Rehabilitation Centre (NVRC); 4) PT Omron Manufacturing of Indonesia (ILO, 2011).

\section{Kesimpulan}

Terlepas dari telah dibuatnya segala macam peraturan mengenai kuota penerimaan tenaga kerja dengan disabilitas fisik pada sekor kerja formal di Indonesia, namun pada pelaksanaannya masih belum sesuai dengan harapan. Pertama, belum terlaksananya dengan baik kesamaan hak dalam mendapatkan pekerjaan bagi disabilitas fisik pada sektor kerja formal, sehingga orang dengan disabilitas yang mempunyai kemampuan untuk dapat bekerja dan mempunyai tanggung jawab yang sama seperti orang pada umumnya belum dapat tersalurkan. Kedua, faktor internal dan faktor eksternal dalam penerimaan diri tenaga kerja dengan disabilitas fisik belum benar-benar diperhatikan pada perusahaan yang sudah menerima tenaga kerja dengan disabilitas sebagai karyawannya. 
Ketiga, kesulitan orang dengan disabilitas fisik dalam aksesibilitas mendapatkan pendidikan formal atau informal demi menunjang kemampuan memasuki dunia kerja pada sektor formal dapat menjadi salah satu faktor penghambat, karena pendidikan merupakan bekal terpenting dalam memberikan ilmu pengetahuan dan kemampuan bagi semua orang, tidak terkecuali orang dengan disabilitas fisik. Keempat, belum adanya sanksi tegas bagi perusahaan, kementerian, ataupun BUMN yang menolak adanya tenaga kerja dengan disabilitas fisik membuat sebagian besar pekerjaan pada sektor formal belum mulai menerapkan penerimaan pada tenaga kerja dengan disabilitas fisik.

Berdasarkan gambaran kesimpulan tersebut, penulis merekomendasikan agar: 1) perlu lebih digencarkan lagi sosialisasi mengenai kuota bagi orang dengan disabilitas fisik dan kemampuan mereka dalam bekerja di sektor formal; 2) pihak pemberi kerja perlu merancang dan melakukan pendampingan dan pembinaan kerja bagi orang dengan disabilitas agar keterampilan dan kemampuan orang dengan disabilitas fisik secara bertahap dapat ditingkatkan; 3) membukakan akses pelatihan dan pendidikan bagi orang dengan disabilitas fisik agar mampu mencapai standar tingkat pendidikan dan pelatihan yang diperlukan oleh tempat bekerja; dan 4) aturan hukum dalam pelaksanaan aturan pemerintah mengenai kesempatan kerja bagi orang dengan disabilitas fisik perlu ditegakkan dan terus di monitor implementasinya secara berkala, sehingga dapat diketahui keadaan sebenarnya di lapangan.

\section{Daftar Pustaka}

Effendi, A.B., Yunianto, dan Rahaditya. (2017). Implementasi Diversity Program Bagi Tenaga Kerja Penyandang Disabilitas Pada Pt. Wangta Agung Kota Surabaya. Indonesian Journal of Disability Studies (IJDS).

Fatmawati, S. (2015). Penilaian Keadilan Distributif Kesempatan Kerja oleh

Tunadaksa. Semarang: Skripsi Universitas Negeri Semarang.

Faturochman. (2012). Keadilan Perspektif Psikologi. Yogyakarta: Pustaka Pelajar. Feminasary, Denis Rangga. (2017). Implementasi Program Pelatihan Kerja terhadap Peningkatan Kesempatan Kerja bagi Orang dengan Disabilitas tahun 2016. Yogyakarta: Skripsi Universitas Muhammadiyah Yogyakarta. Hallahan, D. P., \& Kauffman, J. M. (2006). Exceptional Children: An Introduction to Special Education (10th ed). Boston: Pearson.

ILO. (2011). Good Case Practices on Inclusion of Persons with Disabilities in 
- Monica Kristiani Widhawati, Meilanny Budiarti Santoso, dan Nurliana Cipta Apsari

Indonesia: Opening Opportunities towards Decent Work, July, 2011, Jakarta, Indonesia. Jakarta: ILO.

Macy, G. (1996). Accommodating Employees with Disabilities: A Matter of

Attitude. Journal of Managerial Issues, Vol 8, No. 1. Published by Pittburg State University, Inc. United States of America.

Margaretha, M. (2015). Disabilitas dalam Ketangguhan: Berangkat dari Sumberdaya yang Belum Termanfaatkan. Indonesia: Arbeiter Samariter Bund.

Martini, D, dan Hartini, M.N. (2012). Hubungan antara Penerimaan Diri dengan Kecemasan Menghadapi Dunia Kerja pada Tunadaksa di UPT Rehabilitasi Sosial Cacat Tubuh Pasuruan, Juni 2012, Surabaya, Indonesia. Surabaya: Skripsi Universitas Airlangga.

Miller, F. A. and Katz, J. H. (2002). The Inclusion Breakthrough: Unleashing the Real Power of Diversity. San Francisco: Berrett-Koehler Publishers.

Pertiwi, A. (2011). Peran Balai Rehabilitasi Sosial Distrarastra Pemalang II dalam Mengembangkan Kemandirian Penyandang Tunanetra. Semarang: Skripsi Universitas Negeri Semarang.

Poerwanti, S. D. (2017). Pengelolaan Tenaga Kerja Difabel untuk MewujudkanWorkplace Inclusion.

Pusdatin Kemsos RI. (2012). Rekapitulasi Data Penyandang Masalah Kesejahteraan Sosial (PMKS) Per Provinsi Tahun 2012. Diakses pada 24 Mei 2018 dari http://www.kemsos.go.id/unduh/PMKS/Rekap_PMKS_2012. pdf

Santoso, M.B. \& Apsari, N.C. (2017). Perubahan Paradigma dalam Disabilitas. Intermestics Vol. 1 No. 2, hal. 166-176.

Peraturan Pemerintah Republik Indonesia Nomor 33 Tahun 2013 Tentang Perluasan Kesempatan Kerja.

Undang-undang Nomor 4 Tahun 1997 Tentang Penyandang Cacat Undang-Undang Nomor 8 Tahun 2016 Tentang Penyandang Disabilitas Undang-undang Nomor 13 Tahun 2003 Tentang Ketenagakerjaan Undang-undang Nomor 19 Tahun 2011 Tentang Pengesahan Convention on the Right of Person with Disabilities (Konvensi Mengenai Hak-hak Orang dengan disabilitas).

United Nations Convention on the Rights of Persons with Disabilities (UNCRPD) Tahun 2011. 